\title{
ORCHIDEE-SRC v1.0: an extension of the land surface model ORCHIDEE for simulating short rotation coppice poplar plantations
}

\author{
T. De Groote ${ }^{1,2}$, D. Zona ${ }^{1, *}$, L. S. Broeckx ${ }^{1}$, M. S. Verlinden ${ }^{1}$, S. Luyssaert $^{3}$, V. Bellassen ${ }^{4, * *}$, N. Vuichard $^{3}$, \\ R. Ceulemans ${ }^{1}$, A. Gobin ${ }^{2}$, and I. A. Janssens ${ }^{1}$ \\ ${ }^{1}$ Research Group of Plant and Vegetation Ecology, Department of Biology, University of Antwerp, Universiteitsplein 1, \\ 2610 Wilrijk, Belgium \\ ${ }^{2}$ VITO, Boeretang 200, 2400 Mol, Belgium \\ ${ }^{3}$ CEA-CNRS-UVSQ, UMR8212 - Laboratoire des sciences du climat et de l'environnement (LSCE), Orme des Merisiers, \\ 91191 Gif-sur-Yvette, France \\ ${ }^{4}$ CDC Climat, 47 rue de la Victoire, 75009 Paris, France \\ *now at: Department of Animal and Plant Sciences, The University of Sheffield, Western Bank, Sheffield S10 2TN, UK \\ ** now at: INRA, 147 rue de l'Université, 75000 Paris, France
}

Correspondence to: T. De Groote (toon.degroote@uantwerpen.be)

Received: 12 November 2013 - Published in Geosci. Model Dev. Discuss.: 23 June 2014

Revised: 30 December 2014 - Accepted: 19 April 2015 - Published: 20 May 2015

\begin{abstract}
Modelling biomass production and the environmental impact of short rotation coppice (SRC) plantations is necessary for planning their deployment, as they are becoming increasingly important for global energy production. This paper describes the modification of the widely used land surface model ORCHIDEE for stand-scale simulations of SRC plantations.

The model uses weather data, soil texture and speciesspecific parameters to predict the aboveground (harvestable) biomass production, as well as carbon and energy fluxes of an SRC plantation. Modifications to the model were made to the management, growth, and allocation modules of ORCHIDEE.

The modifications presented in this paper were evaluated using data from two Belgian poplar-based SRC sites, for which multiple measurements and meteorological data were available. Biomass yield data were collected from 23 other sites across Europe and compared to 22 simulations across a comparable geographic range. The simulations show that the model predicts very well aboveground (harvestable) biomass production (within measured ranges), ecosystem photosynthesis $\left(R^{2}=0.78, \mathrm{NRMSE}=0.064, \mathrm{PCC}=0.89\right)$ and ecosystem respiration $\left(R^{2}=0.95, \quad \mathrm{NRMSE}=0.078\right.$
\end{abstract}

PCC $=0.91)$. Also soil temperature and soil moisture are simulated adequately, but due to the simplicity of the soil moisture simulation, there are some discrepancies, which also influence the simulation of the latent heat flux.

Overall, the extended model, ORCHIDEE-SRC, proved to be a tool suitable for predicting biomass production of SRC plantations.

\section{Introduction}

In recent years, a great deal of research has gone into the development of renewable energy as a way to sustain energy production without contributing to climate change. The Europe 2020 headline targets of the European Commission state that by 2020 greenhouse gas emissions should be $20 \%$ lower than in 1990 and $20 \%$ of the European energy has to be renewable (EC, 2010). The National Renewable Energy Action Plan (NREAP) predicts that in Europe $34.3 \%$ of the electricity production and $21.3 \%$ of the heating and cooling energy requirement will come from renewable energy production by 2020 (Zervos et al., 2011). An important share of this renewable energy production will come from biomass. Both annual 
and perennial energy crops and biomass residues from agriculture, forestry and processing industries can be used.

Short rotation coppice (SRC) plantations are perennial energy crops with fast growing tree species, mostly poplar (Populus spp.) or willow (Salix spp.), that are intensively managed in a coppice system (Herve and Ceulemans, 1996; Aylott et al., 2008). The rotation duration typically ranges from 2 to 5 years. At the end of the rotation the shoots are cut back to the ground in winter and the stumps resprout the next spring. The harvested wood is then dried and used for energy production. Management intensity of an SRC plantation is thus higher than in traditional forests but less than in food crops (Hansen, 1991).

Because of the growing societal demand for energy from biomass, SRC plantations are likely to become more widespread, although the full consequences on the carbon (C), water and energy budgets are not yet fully understood. For this reason models are needed that can simulate the larger-scale effects of wide-spread SRC use, which are sufficiently general to allow application at larger scales while being specific in the essential details.

The objective of this study is to further develop an existing land surface model called ORCHIDEE, to have the model simulate the $\mathrm{C}$ and water fluxes of SRC plantations over a range of site conditions. In the future we want to use this model to test a number of management scenarios across Europe to study the variation in the management effects on biomass production and $\mathrm{CO}_{2}$ uptake. To this aim we made changes to the management, growth and allocation modules of ORCHIDEE, adjusted the parameterization and evaluated the performance of the adapted model against site-level information from two operationally managed SRC stands in Belgium.

\section{Materials and methods}

\subsection{Model description}

ORCHIDEE is a mechanistic land surface model that was designed to operate from regional to global scales. The model is composed of two components: (i) SECHIBA, which computes the energy and hydrology budget on a half-hourly basis, and (ii) STOMATE, which simulates the carbon cycle on a daily timescale. The equations used by ORCHIDEE are given in Ducoudre et al. (1993), Krinner et al. (2005) and in the online documentation (http://forge.ipsl.jussieu.fr/ orchidee). The source code can be accessed at http://forge. ipsl.jussieu.fr/orchidee/browser/tags/ORCHIDEE_1_9_5.

For these simulations, ORCHIDEE needs seven meteorological variables at a $30 \mathrm{~min}$ interval: wind speed, air pressure, short-wave radiation, long-wave radiation, air temperature, precipitation and specific air humidity. Atmospheric $\mathrm{CO}_{2}$ concentrations are required on a yearly timescale and a representative soil texture for the site is sufficient.
We evaluated the modifications to ORCHIDEE using output variables that are related to the carbon and energy balance: gross primary production (GPP), net ecosystem exchange (NEE), net primary production (NPP), respiration $(R)$, sensible heat $(H)$ and latent heat (LE).

In version r512, the $\mathrm{C}$ in ORCHIDEE is distributed over three main pools: (i) biomass, (ii) litter and (iii) soil carbon. These pools are divided into eight, two and three subpools, respectively. The biomass pool consists of leaves, roots, above- and belowground sapwood, above- and belowground heartwood, fruits (both flowers and fruits) and a carbohydrate reserve. The litter pool is composed of a structural and a metabolic litter pool. The former contains high-lignin litter, with a slow decay rate, while the latter contains lowlignin litter, which decays faster. The soil carbon consists of a fast, a slow and a passive pool, corresponding to the time it takes for the $\mathrm{C}$ in these pools to become biologically available again.

The soil water in r512 is simulated using two layers following the Choisnel scheme (Choisnel, 1977). The bottom layer is always present. The top layer is a dynamic layer that is absent in drier periods and is created when it starts raining. When the top layer fills with rain, the layer expands as the soil profile becomes wetter and ultimately merges with the bottom layer.

The vegetation is classified into 12 plant functional types (Krinner et al., 2005) plus bare soil. In these plant functional types, plants with a similar physiology are grouped together. The SRC simulations in this paper further develop the "temperate deciduous broadleaf forest" functional type.

As an extension to the standard version of ORCHIDEE, ORCHIDEE-FM was developed to include a number of adaptations for forest management (Bellassen et al., 2010). These adaptations include an age-related limitation of leaf area index (LAI) in young stands, an age-related decline in NPP, self-thinning in unmanaged stands and anthropogenic thinning in managed stands. The source code for this extended version can be found at http://forge.ipsl.jussieu.fr/ orchidee/browser/perso/toon.degroote/orchidee_FM.

\subsection{Model modifications to SRC}

\subsubsection{Management modifications}

A first and essential modification was the ability to simulate multiple rotations, including the coppicing of the trees (Supplement, teal sections). Under SRC, the trees are not entirely harvested. A stump of approximately $10 \mathrm{~cm}$ is left, from which the trees can resprout (DEFRA, 2004). To account for this, the biomass of $10 \mathrm{~cm}$ long stumps is calculated using Eq. (1) and remains in the aboveground woody biomass pool, instead of contributing to the exported biomass pool. Contrary to the thinning in ORCHIDEE-FM, only aboveground biomass is removed during the coppicing of a short rotation coppice. 
Table 1. Allometric relations used for the SRC simulation in the ORCHIDEE-FM model and their parameter values. SRC indicates short rotation coppice culture.

\begin{tabular}{|c|c|c|c|}
\hline Formula & Parameter & Value & Unit \\
\hline $\begin{array}{l}f_{\text {vol_bm }} \rightarrow \text { volume }=\frac{\text { biomass }}{\text { density }} \\
f_{\text {bm_vol }} \rightarrow \text { biomass }=\text { volume } \cdot \text { density }\end{array}$ & density & $1.25 \times 10^{5}$ & $\mathrm{gC} \mathrm{m}^{-3}$ \\
\hline $\begin{array}{l}f_{\text {vol_circ }} \rightarrow \text { volume }=\sum \frac{a \cdot\left(\frac{\text { circumference }}{\pi}\right)^{b}}{\text { density }} \\
f_{\text {circ_vol }} \rightarrow \text { circumference }=\pi \cdot\left(\frac{\text { volume.density }}{a}\right)^{1 / b}\end{array}$ & $\begin{array}{l}\text { density } \\
a \\
b\end{array}$ & $\begin{array}{l}1.25 \times 10^{5} \\
0.033 \\
2.6\end{array}$ & $\mathrm{gC} \mathrm{m}^{-3}$ \\
\hline$f_{\text {height_circ }} \rightarrow$ height $=a \cdot$ circumference $^{b}$ & $\begin{array}{l}a \\
b\end{array}$ & $\begin{array}{l}17.2684 \\
0.6791\end{array}$ & \\
\hline
\end{tabular}

$f_{\text {bm_vol }}\left(\sum \frac{L \cdot \operatorname{circ}^{2}}{4 \pi}\right)$

where $L$ is the length of the remaining stump $(0.1 \mathrm{~m})$, circ is the circumference of the individual shoot, which is a variable in ORCHIDEE-FM and $f_{\mathrm{bm} \text { vol }}$ is an allometric function to calculate biomass from volume, as further described in Sect. 2.2.2 and in Table 1.

A second modification was made for the cultivation regime at the site. In ORCHIDEE, trees start their lives as saplings. Contrary to forest tree plantations, SRC plantations are established using cuttings: $20 \mathrm{~cm}$ long hardwood sticks without any roots or leaves. The average carbon content of a cutting was estimated from the average volume and wood density to be $2.5 \mathrm{~g}$ of C. ORCHIDEE was modified to grow SRC from these cuttings (Supplement, turquoise sections). Half of this $\mathrm{C}$ is located in the aboveground sapwood pool of the cutting and the other half in the carbohydrate reserve. The number of cuttings per hectare can be defined in the configuration file when running the model.

\subsubsection{Growth modifications}

Because ORCHIDEE is a big leaf model and does not simulate individual trees, ORCHIDEE-FM uses allometric relations to convert and partition biomass. There are five allometric relations to convert stem biomass into stem volume, stem volume into stem biomass, circumference into stem volume, stem volume into circumference and circumference into height (Table 1; Supplement, blue sections). The functions $f_{\text {vol_bm }}, f_{\text {bm_vol }}, f_{\text {vol_circ }}$, and $f_{\text {circ_vol }}$ are used to partition the biomass into circumference categories and to calculate the biomass of the initial hardwood cuttings from which the plantation is started. The function $f_{\text {height_circ }}$ calculates the height from the circumference. This height is used to calculate LAI and roughness height. The roughness height is important in calculating the aerodynamic resistance. These standard relations were parameterized using data from the
Boom site, one of the two SRC sites that we used for parameterization and evaluation (see Sect. 2.3.1).

After coppicing an SRC tree resprouts as a multi-stemmed tree. This was incorporated into to the model as a second growth modification (Supplement, violet sections). The number of shoots with which the tree resprouts depends on the genotype. The variation in the number of stems resprouting after coppicing is very large, ranging from 1 to 25 (Pontailler et al., 1999; Dillen et al., 2013). Here, we adopted an average across the many genotypes of two stems after the first coppicing and four stems after the subsequent coppicing.

A final growth adaptation was made to the fine root growth. In ORCHIDEE, the senescence of the leaves and fine roots occurs simultaneously by the same phenological trigger. For SRC simulations, we decoupled the root mortality from the leaf senescence and included a turn-over time (Supplement, yellow sections). The poplar fine roots now stay alive for 6 months after their formation, an average lifetime observed in the field (Coleman et al., 2000; Block et al., 2006). The onset of fine root growth remains coupled with the phenological trigger for leaf growth.

\subsubsection{Allocation modifications}

A poplar tree can become sexually mature from the age of 5 years onwards, depending on the genotype (Dickmann and Stuart, 1983; Muhle Larsen, 1963). Because the duration of most SRC rotations is under 5 years, SRC-grown poplars will never produce flowers or seeds. The same holds for the sapwood to heartwood conversion. To account for this in the model, no carbon is allocated to the reproduction pool (Supplement, red sections), and no aboveground sapwood is converted into heartwood (Supplement, brown sections) when the last coppicing was less than 5 years ago.

The tree species used in SRC plantations are fast-growing tree species that reach a large leaf area as fast as they can. The standard allocation to leaves in ORCHIDEE-FM is strictly constrained by the maximum leaf area index $\left(\mathrm{LAI}_{\max }\right)$ for that year. This $\mathrm{LAI}_{\max }$ evolves slowly, as the stand grows 
Table 2. Parameter values that were changed between the standard version of ORCHIDEE-FM and the adapted version for SRC simulation. PFT indicates plant functional type, $\mathrm{LAI}_{\max }$ the maximal leaf area index, $V_{\mathrm{c}, \max }$ the maximum rate of carboxylation, $J_{\max }$ the maximum electron transport rate, $H_{\text {root }}$ the exponential decay factor of the root profile, $\rho_{\text {leaf,SW }}$ the short-wave leaf albedo, $\rho_{\text {leaf,LW }}$ the long-wave leaf albedo.

\begin{tabular}{llrr}
\hline Parameter & Unit & ORCHIDEE PFT 6 & ORCHIDEE-SRC \\
\hline LAI $_{\max }$ & $\mathrm{m}^{2} \mathrm{~m}^{-2}$ & 4.5 & 2.5 \\
$V_{\mathrm{c}, \max }$ & $\mu \mathrm{mol} \mathrm{m}^{-2} \mathrm{~s}^{-1}$ & 55 & 130 \\
$J_{\max }$ & $\mu \mathrm{mol} \mathrm{m}^{-2} \mathrm{~s}^{-1}$ & 70 & 180 \\
$H_{\text {root }}$ & & 0.8 & 1.5 \\
$\rho_{\text {leaf,SW }}$ & & 0.06 & 0.20 \\
$\rho_{\text {leaf,LW }}$ & & 0.22 & 0.30 \\
\hline
\end{tabular}

and the canopy closes. The high planting density and the different phenology of poplars in SRC plantations do not fit this scheme. Data show that, for SRC plantations, this limitation is only present in the first 1-2 years. Therefore, we adapted LAI $_{\max }$ in the model such that it is only limited in the first year and allowed reaching the plant functional type-specific $\mathrm{LAI}_{\max }$ from year 2 onwards (Supplement, green sections).

After coppicing, poplar trees allocate almost no carbon to the growth of coarse roots. To simulate this effect, the trees in the extended ORCHIDEE model try to maintain a prescribed, structurally logical, root-shoot ratio. When the root-shoot ratio deviates from this prescribed ratio by more than $10 \%$, such as after removal of the entire shoot biomass, $95 \%$ of the $\mathrm{C}$ allocated to wood production is allocated to the aboveground part (Supplement, lime sections).

\subsubsection{Parameterization}

The default parameters in ORCHIDEE were compared to measurements from the POPFULL site (see Sect. 2.3.2). A number of parameters (Table 2) were changed based on this comparison (Supplement, pink sections). Parameters that were in the range of the measured data were left unchanged. A first parameter is $\mathrm{LAI}_{\max }$. This is the maximal LAI that the trees can reach. The next two parameters $V_{\mathrm{c}, \max }$ (maximum carboxylation rate) and $J_{\max }$ (maximum electron transport rate) are photosynthetic parameters. When these parameters are higher, photosynthesis will be higher. Next, $H_{\text {root }}$ is the exponential decay factor of the root profile. This parameter describes the distribution of the roots in the soil and therefore influences the water availability to the plant. Finally, $\rho_{\text {leaf, SW }}$ and, $\rho_{\text {leaf,LW }}$ are the short-wave and long-wave leaf albedo. These parameters determine how much of the incoming radiation is absorbed by the leaves and thus influence the energy uptake of the trees.

\subsection{Data description}

\subsubsection{Boom site}

The Boom site was a poplar-based SRC plantation operating from April 1996 until November 2011 in Boom, near Antwerp, Belgium $\left(51^{\circ} 05^{\prime} \mathrm{N}, 4^{\circ} 22^{\prime} \mathrm{E}\right.$; $5 \mathrm{~m}$ above sea level). The plantation was established on a 0.56 ha former landfill, which was covered with a $2 \mathrm{~m}$ thick soil layer. Seventeen different poplar (Populus spp.) genotypes, belonging to six parentage lines, were planted in April 1996 in a doublerow design with inter-row distances of 0.75 and $1.50 \mathrm{~m}$ and a spacing of $0.90 \mathrm{~m}$ within the rows, resulting in a planting density of 10000 cuttings ha ${ }^{-1}$. The plantation was harvested in December 1996, January 2001, February 2004, February 2008 and November 2011: 1 establishment year and four subsequent rotations of each 4, 3, 4 and 4 years, respectively.

At this site dendrometric measurements included aboveground biomass, tree height and circumference at $22 \mathrm{~cm}$ above ground level. A more complete description of the site and the plant materials has been provided by Laureysens et al. (2003) and Casella and Ceulemans (2002). The evolution of growth, biomass production and yield has been described in detail by Dillen et al. $(2011,2013)$.

\subsubsection{POPFULL site}

The operationally managed POPFULL site was established in April 2010 in Lochristi, near Ghent, Belgium $\left(51^{\circ} 07^{\prime} \mathrm{N}\right.$, $3^{\circ} 51^{\prime} \mathrm{E}$; $6 \mathrm{~m}$ above sea level), on 18.4 ha of former pasture and cropland. Twelve different poplar (Populus spp.) genotypes and three willow (Salix spp.) genotypes were planted in a double-row design with inter-row distances of 0.75 and $1.50 \mathrm{~m}$ and a spacing of $1.10 \mathrm{~m}$ within the rows, resulting in a planting density of 8000 cuttings ha ${ }^{-1}$. The plantation was harvested for the first time in February 2012.

At this site, an eddy-covariance tower was erected (Zona et al., 2013a, b, 2014). The height of the tower varied between 3 and $6 \mathrm{~m}$, depending on canopy height. From this tower, $\mathrm{CO}_{2}$ and $\mathrm{H}_{2} \mathrm{O}$ fluxes were measured. Furthermore, leaf phenology was monitored and LAI was regularly measured. Soil temperature and soil moisture were also monitored during 2011. At the end of each growing season, the biomass production was estimated from stem circumference measurements and site-specific allometric relations.

A complete description of this site is given in Broeckx et al. (2012), while the eddy-covariance flux measurements have been described in detail by Zona et al. (2013a, b, 2014) and the carbon budget was calculated by Verlinden et al. (2013b). 


\subsubsection{European biomass sites}

For the evaluation of aboveground standing woody biomass production across Europe, we used biomass measurements found in Njakou Djomo et al. (2015). From their list of sites, we selected the 23 sites that were not irrigated and had poplar trees (Table 3).

Because meteorological data of sufficient resolution and a detailed site description for these sites were not available, we could not perform a site-by-site comparison. Therefore, we collected meteorological data from 22 different European sites in a similar geographical range on the European Fluxes Database Cluster (http://gaia.agraria.unitus.it/, 1 September 2014) to run our simulations. This way we could compare the range and trend of aboveground woody biomass production along the latitudinal gradient, as well as along the annual precipitation gradient and the average annual temperature gradient,

We selected sites with a public data access and open data use policy, for which data were available for a minimum of 5 years (Table 3 ). Using this meteorological data, we ran the model for 20 years, to calculate the mean annual aboveground standing woody biomass production. For these simulations we chose a planting density of 10000 trees ha $^{-1}$ and a rotation cycle of 2 years.

\subsection{Simulation setup}

Before running the actual simulations, a spinup was run to initialize the soil carbon pool for every site. For this spinup the model was used without SRC modifications, with the standard "temperate deciduous broadleaf forest" plant functional type. This spinup is performed by running the model with the available input data repeatedly, until a soil carbon equilibrium is reached. Because this takes a very long time, a part of this spinup is executed with simplified versions of the model, i.e. teststomate and forcesoil. Teststomate deactivates sechiba, thus only running the daily processes, instead of half-hourly processes, hereby accelerating the model 48 times, reaching a steady state for the non-soil carbon pools. Forcesoil only uses the ORCHIDEE's soil carbon module, reaching a steady state for the soil carbon pools.

For this spinup, the model was first run for 20 years, followed by 50 years with teststomate. This was repeated three times. Thereafter, the model was run for 40 years, followed by 1000 years with forcesoil and finally another 260 years of the full model. This accumulates to a total of 1510 years, of which 360 were run with the full model. The end state of the spinups is then used as initial state for the actual simulations.

For the simulation of the POPFULL site, the soil fractions were set to the average of the measured data ( $86 \%$ sand, $3 \%$ silt, $11 \%$ clay). For the Boom site, no texture data were available. Being a former landfill, the soil description for this site was very imprecise, mentioning only the broader texture classes, loam, sandy loam and silty loam. Therefore, the stan- dard texture values (49\% sand, $29 \%$ silt, $22 \%$ clay), which correspond to loam, were used for the Boom site. The number of cuttings was set to $8000 \mathrm{ha}^{-1}$ for the POPFULL site and $10000 \mathrm{ha}^{-1}$ for the Boom site. The soil depth was set to $1 \mathrm{~m}$ for both sites.

\subsection{Data processing}

On the POPFULL site, meteorological data for 2010 and 2011 were collected together with the eddy-covariance flux data. Since the measurements did not start until June 2010, this gap was filled using data from a nearby station (Melle) from the Royal Meteorological Institute (RMI). For the Boom site, meteorological data were used from a nearby field site (Brasschaat).

For the POPFULL site, measured eddy-covariance fluxes (GPP, $R_{\text {eco }}$, NEE, $H$ and LE) were used to evaluate the model outputs. These data were not related to the data that were used to calibrate the model. NEE, $H$ and LE were measured directly by the eddy-covariance technique, but for GPP and $R_{\text {eco }}$ an approximation had to be calculated using flux partitioning. Here, GPP and $R_{\text {eco }}$ were calculated using the online eddy-covariance gap-filling and flux-partitioning tool of the Max Planck Institute for Biogeochemistry (http://www.bgc-jena.mpg.de/ MDIwork/eddyproc/), which is based on the standardized methods described in Reichstein et al. (2005).

To quantify the model fit of the modelled fluxes with the measured data, three statistical criteria for model efficiency were evaluated using the half hourly data. The coefficient of determination $\left(R^{2}\right)$, the normalized root mean square error (NRMSE) and a Pearson correlation coefficient (PCC) were calculated. The root mean square error was normalized by dividing it by the range of values of the measured variable.

$R^{2}$ explains the variance in model performance by comparing it to the data variation. The NRMSE gives a measure for the accumulated model error. The PCC shows how well the data are correlated. While $R^{2}$ and PCC give a measure for how well the trends in the data are simulated, NRMSE gives a measure for the total cumulated model error.

To visualize the model fit, the modelled fluxes were plotted against the measured weekly averages.

To compare the total fluxes, the half hourly data were cumulated. Since there were no flux measurements before June 2010, this gap was filled with the modelled data.

\section{Results and discussion}

The relative impact of the model modifications on the accuracy of the model simulations by the extended model, ORCHIDEE-SRC, relative to ORCHIDEE-FM is presented in Fig. 1. Biomass production and all fluxes were simulated better or equally well by the extended model. Figure 2 also shows the improvement in the simulation of biomass produc- 


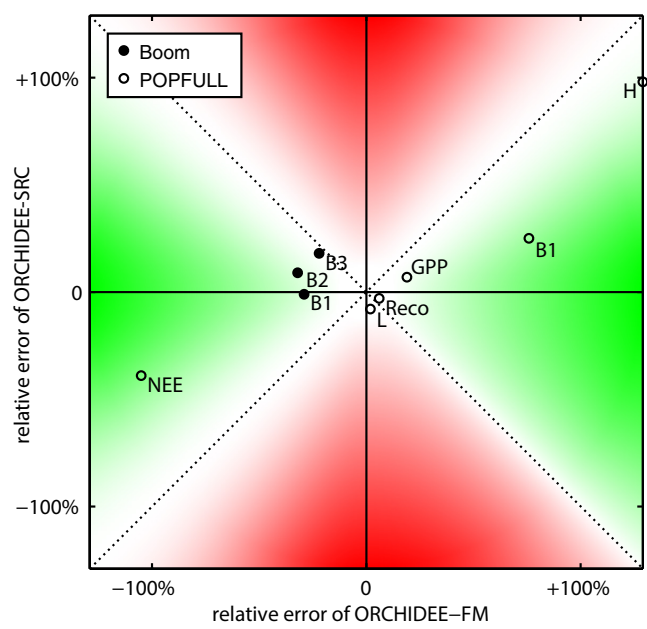

Figure 1. Comparison between the performance of the ORCHIDEE-SRC and ORCHIDEE-FM. The relative error was calculated as the relative difference between the field measurements and the model simulations. The green background indicates an improvement by the extended model relative to ORCHIDEE-FM, and the red background indicates a deterioration of the model results from the extended model. A darker colour indicates a more pronounced difference. The Boom site simulations are shown as filled circles, and the POPFULL site simulations are shown as open circles. The letters next to the symbol are as follows: GPP indicates gross primary productivity cumulated over the 2 measurement years; Reco the ecosystem respiration cumulated over the 2 measurement years; NEE the net ecosystem exchange cumulated over the 2 measurement years; LE the latent heat cumulated over the 2 measurement years; $H$ the sensible heat cumulated over the 2 measurement years; $B_{x}$ the aboveground woody biomass production of rotation $x$.

tion compared to ORCHIDEE-FM. Detailed analyses of the model simulations of biomass production, carbon fluxes, energy fluxes and soil parameters are given in the following sections.

\subsection{Biomass evaluation}

\subsubsection{Site level}

For the Boom site, the yearly aboveground biomass measurements were compared to the model output (Fig. 2a). From the third year of the first rotation onwards, the model predictions were well within the range of measured values and approximate the average aboveground woody biomass production. Measurements were available for 17 genotypes, hence the wide range in observations. The low measured values in the first 2 years might be explained by strong competition from weeds, which was observed in the starting years of this plantation (R. Ceulemans, personal communication, 2013). The low values for the year 1998 - a cold wet year - are explained by a severe rust infection at the site (Al Afas et al., 2008).
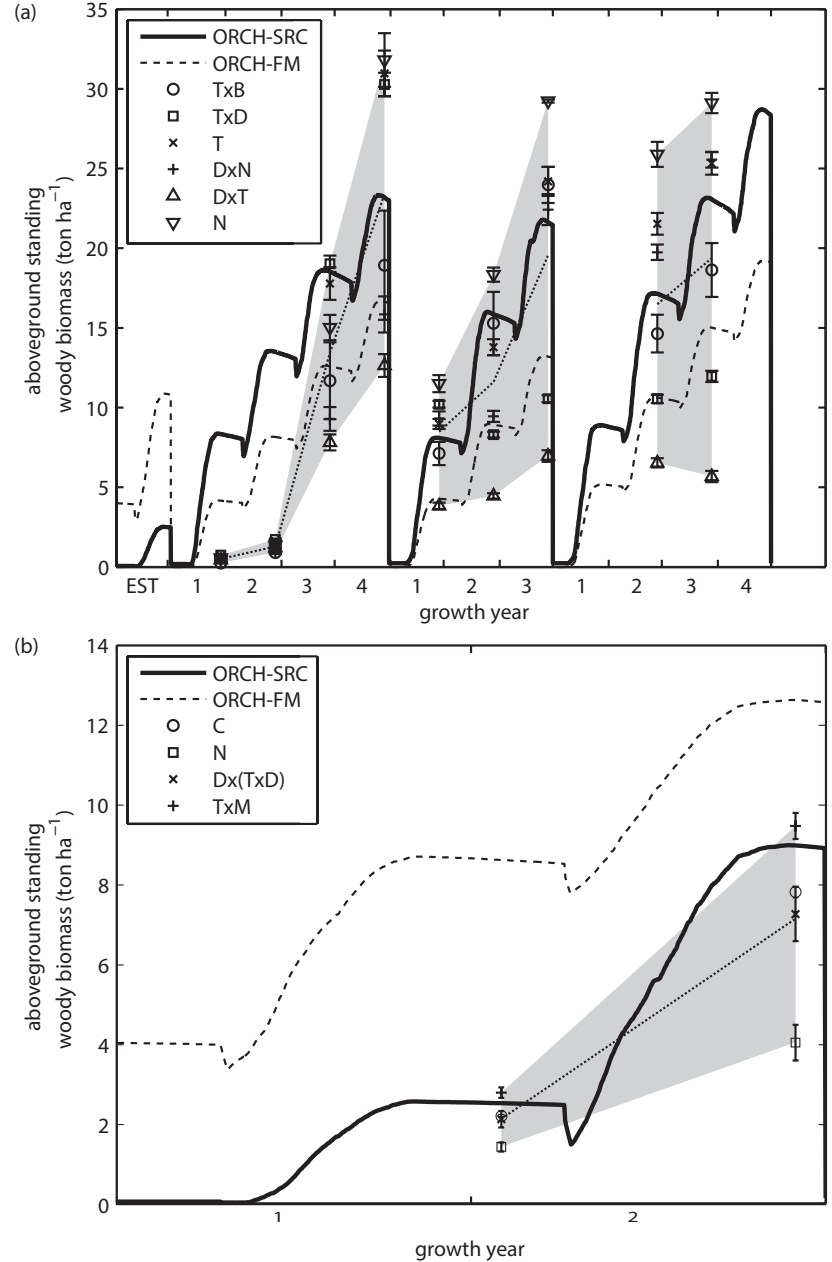

Figure 2. The simulated standing aboveground woody biomass (a) for the Boom site and (b) for the POPFULL site. The solid black line is the biomass simulated by the extended model, ORCHIDEESRC. The dashed line is the biomass simulated by the standard version of ORCHIDEE-FM, with only coppicing implemented. The symbols are the different parentages of the poplars at that site, and the grey area is the range of measured biomass. The parentages are Populus trichocarpa $\times P$. balsamifera $(\mathrm{T} \times \mathrm{B}), P$. trichocarpa $\times P$. deltoides $(\mathrm{T} \times \mathrm{D})$, P. trichocarpa $(\mathrm{T}), P$. deltoides $\times P$. nigra $(\mathrm{D} \times \mathrm{N}), P$. deltoides $\times P$. trichocarpa $(\mathrm{D} \times \mathrm{T})$, $P$. nigra $(\mathrm{N}), P$. canadensis $(\mathrm{C})$, P. deltoides $\times(P$. trichocarpa $\times P$. deltoides $)(\mathrm{D} \times(\mathrm{T} \times \mathrm{D}))$, and $P$. trichocarpa $\times P$. maximowiczii $(\mathrm{T} \times \mathrm{M})$.

The modelled aboveground biomass for the POPFULL site was also well within the measured ranges (Fig. 2b), although the prediction for the first year was in the lower limits of the range.

\subsubsection{Europe}

Since we could not simulate the same sites as we collected measurements for, we compared the average annual aboveground standing woody biomass for the sites across Europe 
Table 3. Biomass validation site info for the simulated sites, acquired from the European Fluxes Database Cluster (http://gaia.agraria.unitus. it/, 1 September 2014) and the measured sites, acquired from Njakou Djomo et al. (2015).

\begin{tabular}{|c|c|c|c|c|c|c|c|c|c|c|c|}
\hline \multicolumn{6}{|c|}{ Simulations } & \multicolumn{6}{|c|}{ Measurements } \\
\hline Country & $\begin{array}{l}\text { Site } \\
\text { name }\end{array}$ & Latitude & Longitude & $\begin{array}{r}\text { Annual } \\
\text { temp } \\
{ }^{\circ} \mathrm{C}\end{array}$ & $\begin{array}{r}\text { Annual } \\
\text { precip } \\
\text { mm }\end{array}$ & Country & $\begin{array}{l}\text { Site } \\
\text { name }\end{array}$ & Latitude & Longitude & $\begin{array}{r}\text { Annual } \\
\text { temp } \\
{ }^{\circ} \mathrm{C}\end{array}$ & $\begin{array}{r}\text { Annual } \\
\text { precip } \\
\mathrm{mm}\end{array}$ \\
\hline PT & Mitra IV (Tojal) & $38.48^{\circ} \mathrm{N}$ & $8.02^{\circ} \mathrm{W}$ & 14.2 & 588 & IT & Caramagna Piemonte & $44.47^{\circ} \mathrm{N}$ & $7.44^{\circ} \mathrm{E}$ & 12.5 & 700 \\
\hline ES & Las Majadas del Tietar & $39.94^{\circ} \mathrm{N}$ & $5.77^{\circ} \mathrm{W}$ & 16.1 & 721 & IT & Lombriasco & $44.51^{\circ} \mathrm{N}$ & $7.38^{\circ} \mathrm{E}$ & 13.0 & 650 \\
\hline IT & Collelongo & $41.85^{\circ} \mathrm{N}$ & $13.59^{\circ} \mathrm{E}$ & 7.3 & 1160 & $\mathrm{CZ}$ & Nová Olešná & $49.17^{\circ} \mathrm{N}$ & $15.16^{\circ} \mathrm{E}$ & 7.2 & 730 \\
\hline IT & Roccarespampani 1 & $42.41^{\circ} \mathrm{N}$ & $11.93^{\circ} \mathrm{E}$ & 15.6 & 840 & $\mathrm{CZ}$ & Bystřice & $49.21^{\circ} \mathrm{N}$ & $12.48^{\circ} \mathrm{E}$ & 5.7 & 800 \\
\hline FR & Mauzac & $43.39^{\circ} \mathrm{N}$ & $1.29^{\circ} \mathrm{E}$ & 12.7 & 566 & $\mathrm{CZ}$ & Smilkov & $49.36^{\circ} \mathrm{N}$ & $14.36^{\circ} \mathrm{E}$ & 6.8 & 650 \\
\hline IT & San Rossore & $43.73^{\circ} \mathrm{N}$ & $10.28^{\circ} \mathrm{E}$ & 15.2 & 921 & $\mathrm{CZ}$ & Rosice & $50.03^{\circ} \mathrm{N}$ & $15.42^{\circ} \mathrm{E}$ & 8.5 & 500 \\
\hline FR & Puéchabon & $43.74^{\circ} \mathrm{N}$ & $3.6^{\circ} \mathrm{E}$ & 13.6 & 894 & $\mathrm{DE}$ & Arnsfeld & $50.34^{\circ} \mathrm{N}$ & $13.06^{\circ} \mathrm{E}$ & 7.0 & 625 \\
\hline IT & Lavarone & $45.96^{\circ} \mathrm{N}$ & $11.28^{\circ} \mathrm{E}$ & 6.9 & 1263 & $\mathrm{DE}$ & Großschirma & $50.57^{\circ} \mathrm{N}$ & $13.17^{\circ} \mathrm{E}$ & 7.2 & 820 \\
\hline IT & Renon & $46.59^{\circ} \mathrm{N}$ & $11.43^{\circ} \mathrm{E}$ & 4.5 & 1219 & $\mathrm{DE}$ & Krummenhennersdorf & $50.98^{\circ} \mathrm{N}$ & $13.36^{\circ} \mathrm{E}$ & 7.2 & 820 \\
\hline AT & Neustift & $47.12^{\circ} \mathrm{N}$ & $11.32^{\circ} \mathrm{E}$ & 6.8 & 700 & $\mathrm{BE}$ & Zwijnaarde & $51.02^{\circ} \mathrm{N}$ & $3.43^{\circ} \mathrm{E}$ & 9.8 & 821 \\
\hline $\mathrm{CZ}$ & Lägern & $47.48^{\circ} \mathrm{N}$ & $8.37^{\circ} \mathrm{E}$ & 7.7 & 777 & $\mathrm{BE}$ & Boom & $51.05^{\circ} \mathrm{N}$ & $4.22^{\circ} \mathrm{E}$ & 11.1 & 824 \\
\hline $\mathrm{DE}$ & Wetzstein & $50.45^{\circ} \mathrm{N}$ & $11.46^{\circ} \mathrm{E}$ & 6.5 & 971 & $\mathrm{BE}$ & Lochristi & $51.06^{\circ} \mathrm{N}$ & $3.51^{\circ} \mathrm{E}$ & 9.5 & 726 \\
\hline $\mathrm{DE}$ & Klingenberg & $50.89^{\circ} \mathrm{N}$ & $13.52^{\circ} \mathrm{E}$ & 7.6 & 801 & $\mathrm{DE}$ & Commichau & $51.08^{\circ} \mathrm{N}$ & $12.50^{\circ} \mathrm{E}$ & 8.5 & 680 \\
\hline $\mathrm{DE}$ & Grillenburg & $50.95^{\circ} \mathrm{N}$ & $13.51^{\circ} \mathrm{E}$ & 8.5 & 975 & $\mathrm{DE}$ & Skäßchen & $51.20^{\circ} \mathrm{N}$ & $13.35^{\circ} \mathrm{E}$ & 8.5 & 575 \\
\hline $\mathrm{DE}$ & Tharandt & $50.96^{\circ} \mathrm{N}$ & $13.57^{\circ} \mathrm{E}$ & 8.6 & 871 & $\mathrm{DE}$ & Großthiemig & $51.22^{\circ} \mathrm{N}$ & $13.4^{\circ} \mathrm{E}$ & 8.5 & 575 \\
\hline $\mathrm{DE}$ & Hainich & $51.08^{\circ} \mathrm{N}$ & $10.45^{\circ} \mathrm{E}$ & 8.3 & 779 & $\mathrm{DE}$ & Thammenhain & $51.25^{\circ} \mathrm{N}$ & $12.51^{\circ} \mathrm{E}$ & 8.5 & 575 \\
\hline $\mathrm{BE}$ & Brasschaat & $51.31^{\circ} \mathrm{N}$ & $4.52^{\circ} \mathrm{E}$ & 10.6 & 848 & $\mathrm{DE}$ & Nochten & $51.25^{\circ} \mathrm{N}$ & $14.36^{\circ} \mathrm{E}$ & 8.5 & 650 \\
\hline UK & Pang/Lambourne forest & $51.45^{\circ} \mathrm{N}$ & $1.27^{\circ} \mathrm{W}$ & 12.3 & 658 & $\mathrm{DE}$ & Vetschau & $51.46^{\circ} \mathrm{N}$ & $14.04^{\circ} \mathrm{E}$ & 8.5 & 550 \\
\hline NL & Loobos & $52.17^{\circ} \mathrm{N}$ & $5.74^{\circ} \mathrm{E}$ & 10.0 & 872 & $\mathrm{DE}$ & Methau I & $51.50^{\circ} \mathrm{N}$ & $12.51^{\circ} \mathrm{E}$ & 8.1 & 690 \\
\hline DK & Sorø & $55.49^{\circ} \mathrm{N}$ & $11.64^{\circ} \mathrm{E}$ & 8.4 & 760 & $\mathrm{DE}$ & Methau II & $51.50^{\circ} \mathrm{N}$ & $12.51^{\circ} \mathrm{E}$ & 8.1 & 690 \\
\hline RU & Fyodorovskoye & $56.46^{\circ} \mathrm{N}$ & $32.92^{\circ} \mathrm{E}$ & 5.1 & 524 & $\mathrm{DE}$ & Kuhstorf & $53.23^{\circ} \mathrm{N}$ & $11.15^{\circ} \mathrm{E}$ & 8.2 & 616 \\
\hline FI & Hyytiälä & $61.85^{\circ} \mathrm{N}$ & $24.3^{\circ} \mathrm{E}$ & 4.1 & 555 & $\mathrm{DE}$ & Laage & $53.55^{\circ} \mathrm{N}$ & $12.20^{\circ} \mathrm{E}$ & 8.0 & 630 \\
\hline
\end{tabular}

based on their latitude, average annual temperature and average annual precipitation (Fig. 3).

The simulations were within the range of the measured values and followed their general trends. When comparing with latitude, increasing latitudes increase biomass production up to around $55^{\circ} \mathrm{N}$. The biomass production of simulations for latitudes above $55^{\circ} \mathrm{N}$ start declining again but cannot be compared to measurements, because of lacking data (Fig. 3a). Increasing temperatures have a negative effect on aboveground woody biomass production for both the measurements and the simulations (Fig. 3b). This is probably caused by the negative relation between temperature and precipitation. The simulated aboveground biomass production increases slightly with increasing precipitation (Fig. 3c). This trend is also shown by the measured data, except for two high producing sites in the low precipitation range.

Generally, the measured data had a higher spread, which could be explained by variable factors we could not account for in the general modelling approach. Such factors could include genotype selection, weed competition, rotation length, planting density, etc.

\section{2 $\mathrm{CO}_{2}$ flux evaluation}

The measured $\mathrm{C}$ and energy fluxes at the POPFULL site were compared to the model outputs. Figure 4 depicts both the simulated and observed cumulative GPP, NEE, $H$, LE and $R_{\text {eco. }}$.

During the first year, the calculated and observed GPP values matched well $\left(R^{2}=0.78, \mathrm{NRMSE}=0.064, \mathrm{PCC}=0.89\right.$;
Fig. 4). In winter, measured values established a slight increasing trend, while GPP remained constant in the model outputs. This could either be explained by photosynthesis of weeds, which are not represented in the model, or by errors in the flux partitioning. During the second year, the modelled GPP started rising about 1 month later than the measured values but thereafter caught up with the measurements (Fig. 4). Again, this difference might have been caused by the presence of weeds in the field, which were not accounted for in the model. Another reason for these differences could be the use of different genotypes at the field site, because the model only simulates an average genotype. In 2011, the spring bud flushing date of the different genotypes ranged from day 72 until day 107, which is about a 1-month difference. The modelled bud flush started on day 97, which is well within this observed range, but logically results in a lag of 25 days between observed and simulated date of onset of GPP. After 2 years, the cumulated GPP values were 23.0 and 21.4 $\mathrm{Mg} \mathrm{Cha}^{-1}$ for the model and the measurements, respectively. This difference of $1.6 \mathrm{Mg} \mathrm{Cha}^{-1}$ represents an overestimation by the model of only $7 \%$, well within the uncertainty of eddy-covariance-based GPP estimates (Desai et al., 2008; Richardson et al., 2006).

The modelled $R_{\text {eco }}$ fitted the measurements very well $\left(R^{2}=0.95, \mathrm{NRMSE}=0.078 \mathrm{PCC}=0.91\right)$. The only point of divergence was the dry spell in the summer of the second year. Here, $R_{\text {eco }}$ was underestimated, probably because the model is too sensitive to drought. The accumulated $R_{\text {eco }}$ for the first rotation based on observations was $24.0 \mathrm{Mg} \mathrm{Cha}^{-1}$, 

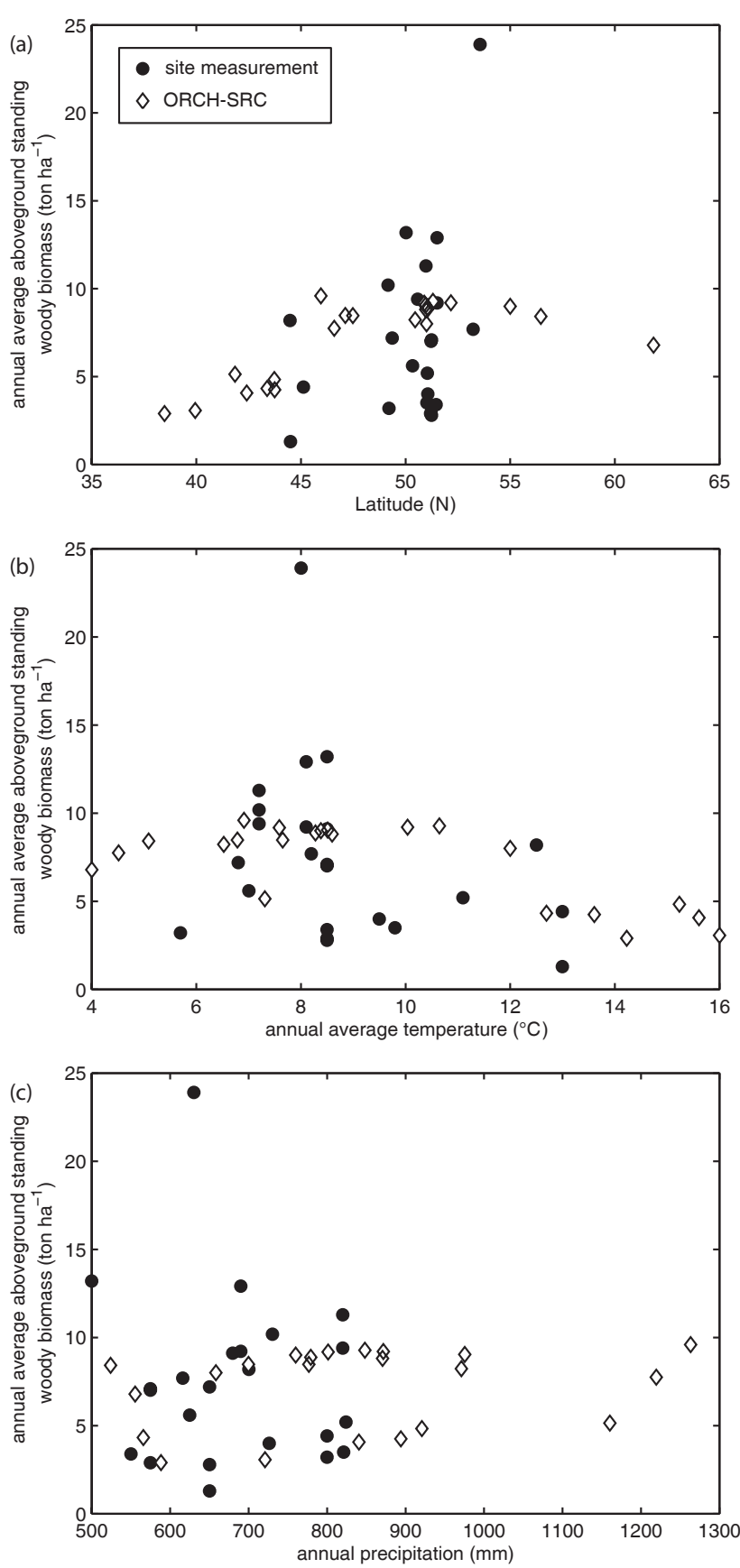

Figure 3. Comparison of aboveground standing woody biomass for ORCHIDEE-SRC simulations (open diamonds) across Europe with site measurements (black circles) across Europe. The biomass is plotted against (a) latitude, (b) annual average temperature and (c) annual precipitation.

while the model predicted $23.3 \mathrm{MgC} \mathrm{ha}^{-1}$ - an underestimation of only $3 \%$.

$\mathrm{C}$ is taken up by photosynthesis (GPP) and emitted through respiration $\left(R_{\mathrm{eco}}\right)$. The resulting net flux is NEE. Small errors in GPP and $R_{\text {eco }}$ might therefore accumulate in NEE giving it a worse fit. When comparing NEE, the fit is not

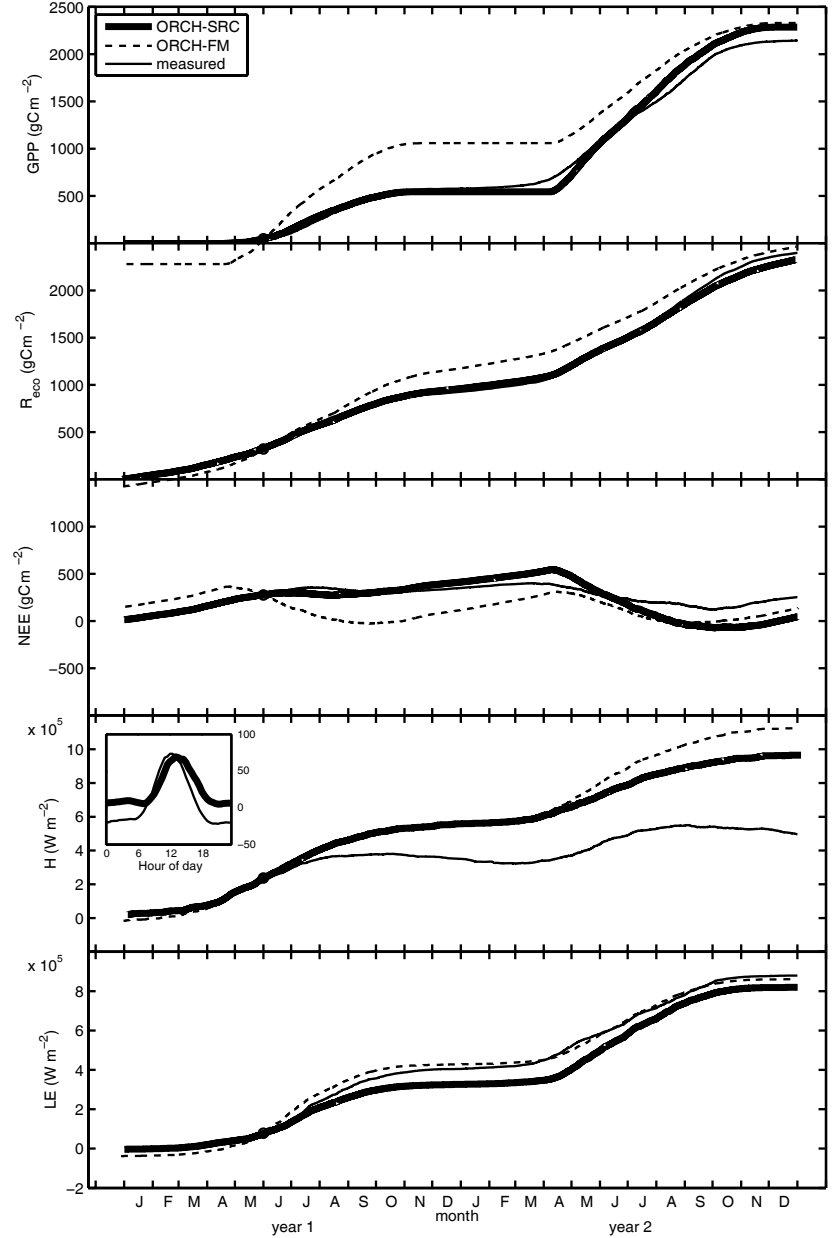

Figure 4. Cumulative fluxes of gross primary production (GPP), ecosystem respiration $\left(R_{\text {eco }}\right)$, net ecosystem exchange (NEE), sensible heat $(H)$ and latent heat (LE) for the POPFULL site. The inset in the graph for sensible heat flux shows the average diurnal cycle of the sensible heat flux. The thin solid lines are the measured values from the eddy-covariance measurements or recalculated from these measurements using the flux-partitioning tool of the Max Planck Institute for Biogeochemistry (http://www.bgc-jena.mpg.de/ $\sim$ MDIwork/eddyproc/). The dashed lines are the model outputs using the standard model ORCHIDEE-FM. The solid thick lines are the model outputs using the modified model ORCHIDEE-SRC. Since there were no flux measurements before June 2010, both simulated and measured values coincide before that date.

as good as for GPP and $R_{\text {eco }}\left(R^{2}=0.51\right.$, NRMSE $=0.069$, $\mathrm{PCC}=0.84)$. In the model results, the plantation switched from emitting $\mathrm{C}$ to taking up $\mathrm{C}$ in July of the first year. In the measured data, this switch occurred only during August, possibly because of the increased $\mathrm{C}$ loss due to the land use change after the plantation establishment (Zona et al., 2013a). During the winter and spring of the second growing season, both the simulated and the measured fluxes indicated a net loss of $\mathrm{CO}_{2}$, but the simulation suggested a stronger source. This difference could probably be explained by the 


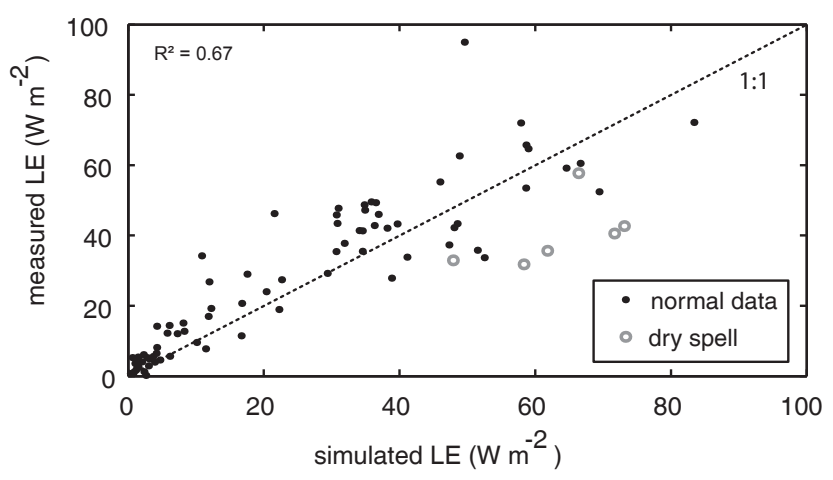

Figure 5. A one-to-one comparison of weekly averages of latent heat (LE) for the POPFULL site, between the model outputs and the measured values. The dotted line is the $1: 1$ line. Weeks $18-23$, which represent the dry spell, are highlighted as grey circles.

presence of weeds on the site, which were not present in the model simulation. The photosynthesis of these weeds partly counteracted the $\mathrm{C}$ losses from soil respiration. From August until October, both the model and the measurements indicated a $\mathrm{C}$ uptake. The model, however, presented a stronger $\mathrm{C}$ sink than the measurements. From October onwards, both modelled and measured data showed a $\mathrm{C}$ source. At the end of the second year, the end of the first rotation, the measurements showed a cumulated net $\mathrm{C}$ loss of $5.4 \mathrm{Mg} \mathrm{ha}^{-1}$, while the model only predicted a $\mathrm{C}$ loss of $3.3 \mathrm{Mg} \mathrm{ha}^{-1}$. The model underestimated the $\mathrm{C}$ loss to the atmosphere by $39 \%$.

A good fit for GPP and $R_{\text {eco }}$ is, however, more important than an accurate simulation of NEE, because they are the real (and large) physical fluxes that occur in the field and are simulated by the model. Also the soil C loss was simulated adequately. The measured soil $\mathrm{C}$ loss was $700 \mathrm{~g} \mathrm{~m}^{-2}$ for the top $15 \mathrm{~cm}$ (Verlinden et al., 2013a), while the model predicted a soil C loss of $740 \mathrm{~g} \mathrm{~m}^{-2}$ over the first rotation.

\subsection{Water and energy flux evaluation}

For $H$, the cumulative plot (Fig. 4) shows diverging lines and an overestimation of $120 \%$ of the cumulative energy loss from $H$ at the end of the rotation $\left(R^{2}=0.36\right.$, $\mathrm{NRMSE}=0.057, \mathrm{PCC}=0.71$ ). The error is probably caused by a stable stratification that often develops in dense plantations at night. Because of this stratification the measured sensible heat flux at night is lower than the simulated flux. The averaged diurnal pattern shown in the inset of Fig. 4 clearly shows this discrepancy. The stratification cannot be represented correctly by the calculation of surface drag, in the way it is implemented in ORCHIDEE. This problem already existed in the model, as described by Krinner et al. (2005). Because $H$ has no impact on the $\mathrm{C}$ or water cycle in the model algorithms, this problem was not considered an issue in this study.

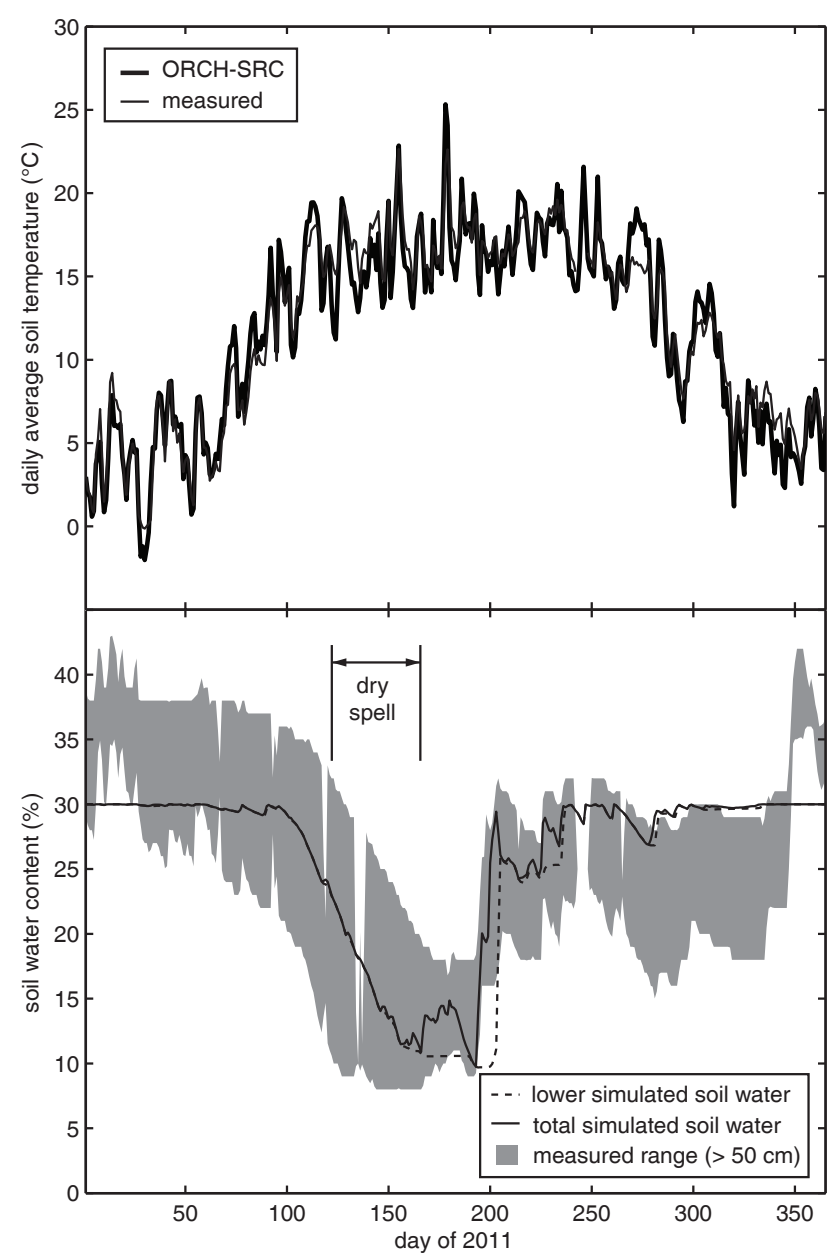

Figure 6. A comparison of modelled and measured soil state variables for 2011 at the POPFULL site. (a) shows the daily average soil temperature simulated (thick) and measured (thin). (b) shows the soil water content. The grey area represents the measured range of soil water content values for the top $50 \mathrm{~cm}$ of the soil. The dotted line is the soil water content of the lower soil water compartment of the model, and the solid line is the total soil water content of the upper and lower soil water compartments.

During the first growing season, LE increased more slowly in the model than can be observed in the measured data $\left(R^{2}=0.68\right.$, NRMSE $=0.055, \mathrm{PCC}=0.78 ;$ Fig. 4). This might be explained by the LAI. The modelled LAI (LAI max $_{\text {max }}$ 0.75 ) for the first year was on the lower end of the measured LAI ranges $\left(\mathrm{LAI}_{\max }\right.$ 0.6-1.8). This lower leaf area consequently resulted in a lower leaf surface to evaporate water from. From November of the first year onward, the cumulative LE curves of the simulations and the measurements keep running in parallel, except for a small period during the second year. This was caused by a dry spell during August. The model slightly underestimated the effect of the drought, allowing the trees to transpire more water. This can be observed in Fig. 5 as the six highlighted dots that represent the 
6 dry weeks that are marked in Fig. 6b. At the end of the rotation, this resulted in a cumulative LE of $880 \mathrm{~kW} \mathrm{~m}^{-2}$ for the measurements and $806 \mathrm{~kW} \mathrm{~m}^{-2}$ for the model, which is an underestimation of $8 \%$ by the model.

\subsection{Soil variable evaluation}

Figure 6a shows the measured and modelled soil temperature during 2011 for the POPFULL site. These are the only data we had available on soil temperature. These data show that the soil temperature was simulated very well by our model $\left(R^{2}=0.955, \mathrm{NRMSE}=0.098, \mathrm{PCC}=0.907\right)$.

For soil moisture, ORCHIDEE only has two soil compartments, of which one is only present after rainfall (Fig. 6b). We compared the total simulated soil water content to the average measured soil water content of the top $50 \mathrm{~cm}$ of soil, which had a reasonable fit $\left(R^{2}=0.976, \mathrm{NRMSE}=0.152\right.$, $\mathrm{PCC}=0.828$ ). Due to the simplicity of the implementation of soil moisture in ORCHIDEE, the model cannot simulate the level of detail that is shown by the measurements. The model does, however, very clearly show the decline of soil water content during the dry spell, as well as the replenishment of the top layer with the precipitation after the dry spell.

\section{Conclusion}

Our validation shows that the modifications to the model ORCHIDEE presented in this paper predict well aboveground harvestable woody biomass. Also gross primary production $\left(R^{2}=0.78, \mathrm{NRMSE}=0.064, \mathrm{PCC}=0.89\right)$ and ecosystem respiration $\left(R^{2}=0.95\right.$, NRMSE $\left.=0.078 \mathrm{PCC}=0.91\right)$ were simulated very well. Also soil temperature and soil moisture are simulated adequately, but due to the simplicity of the soil moisture simulation, there are some discrepancies, which also influence the simulation of the latent heat flux. The annual latent heat flux was, however, simulated reasonably well. Overall the ORCHIDEE-SRC version of the ORCHIDEE model is very well suited to simulate biomass production in SRC plantations.

\section{The Supplement related to this article is available online at doi:10.5194/gmd-8-1461-2015-supplement.}

Acknowledgements. The research leading to these results has received funding from the European Research Council under the European Commission's Seventh Framework Programme (FP7/2007-2013) as ERC grant agreement no. 233366 (POPFULL), the Flemish Hercules Foundation as Infrastructure contract ZW09-06, the Flemish Methusalem Programme, the Research Council of the University of Antwerp, and the Research Foundation - Flanders (FWO; DOFOCO project). We gratefully acknowledge the excellent technical support of Joris Cools and the logistic support of Kristof Mouton at the field site. T. De Groote is a PhD fellow of the Research Foundation - Flanders (FWO) and the Flemish Institute for Technological Research (VITO).

Edited by: A. Ridgwell

\section{References}

Al Afas, N., Marron, N., Van Dongen, S., Laureysens, I., and Ceulemans, R.: Dynamics of biomass production in a poplar coppice culture over three rotations (11 years), Forest Ecol. Manage., 255, 1883-1891, doi:10.1016/j.foreco.2007.12.010, 2008.

Aylott, M. J., Casella, E., Tubby, I., Street, N. R., Smith, P., and Taylor, G.: Yield and spatial supply of bioenergy poplar and willow short-rotation coppice in the UK, New Phytol., 178, 358-370, 2008.

Bellassen, V., Le Maire, G., Dhote, J. F., Ciais, P., and Viovy, N.: Modelling forest management within a global vegetation model Part 1: Model structure and general behaviour, Ecol. Model., 221, 2458-2474, 2010.

Block, R. M. A., Rees, K. C. J., and Knight, J. D.: A review of fine root dynamics in Populus plantations, Agroforest. Syst., 67, 73-84, doi:10.1007/s10457-005-2002-7, 2006.

Broeckx, L. S., Verlinden, M. S., and Ceulemans, R.: Establishment and two-year growth of a bio-energy plantation with fast-growing Populus trees in Flanders (Belgium): Effects of genotype and former land use, Biomass Bioenerg., 42, 151-163, 2012.

Casella, E. and Ceulemans, R.: Spatial distribution of leaf morphological and physiological characteristics in relation to local radiation regime within the canopies of 3-year-old Populus clones in coppice culture, Tree Physiol., 22, 1277-1288, 2002.

Choisnel, E.: Le bilan d'énergie et le bilan hydrique du sol, La Météorologie, 6, 103-133, 1977.

Coleman, M. D., Dickson, R. E., and Isebrands, J. G.: Contrasting fine-root production, survival and soil $\mathrm{CO}_{2}$ efflux in pine and poplar plantations, Plant Soil, 225, 129-139, doi:10.1023/A:1026564228951, 2000.

DEFRA: Growing short rotation coppice - Best practice guidelines for applicants to Defra's energy crops scheme, Department for Environment, Food and Rural Affairs, London, UK, 2004.

Desai, A. R., Richardson, A. D., Moffat, A. M., Kattge, J., Hollinger, D. Y., Barr, A., Falge, E., Noormets, A., Papale, D., Reichstein, M., and Stauch, V. J.: Cross-site evaluation of eddy covariance GPP and RE decomposition techniques, Agr. Forest Meteorol., 148, 821-838, doi:10.1016/j.agrformet.2007.11.012, 2008.

Dickmann, D. and Stuart, K. W.: The culture of poplars in eastern North America, Dept. of Forestry, Michigan State University, East Lansing, Mich. and Dansville, 1983.

Dillen, S. Y., Vanbeveren, S., al Afas, N., Laureysens, I., Croes, S., and Ceulemans, R.: Biomass production in a 15-year-old poplar short-rotation coppice culture in Belgium, Aspects of Applied Biology, 112, 99-106, 2011.

Dillen, S. Y., Djomo, S. N., Al Afas, N., Vanbeveren, S., and Ceulemans, R.: Biomass yield and energy balance of a short-rotation poplar coppice with multiple clones on degraded land during 16 years, Biomass Bioenerg., 56, 157-165, 2013. 
Ducoudre, N. I., Laval, K., and Perrier, A.: Sechiba, a New Set of Parameterizations of the Hydrologic Exchanges at the Land Atmosphere Interface within the Lmd Atmospheric GeneralCirculation Model, J. Climate, 6, 248-273, 1993.

EC: Communication from the commision - Europe 2020 - A strategy for smart, sustainable and inclusive growth. COM 2010; 2020, Final (03/03/2010), European Commission, Brussels, 2010.

Hansen, E. A.: Poplar Woody Biomass Yields - a Look to the Future, Biomass Bioenerg., 1, 1-7, 1991.

Herve, C. and Ceulemans, R.: Short-rotation coppiced vs noncoppiced poplar: A comparative study at two different field sites, Biomass Bioenerg., 11, 139-150, doi:10.1016/09619534(96)00028-1, 1996.

Krinner, G., Viovy, N., de Noblet-Ducoudre, N., Ogee, J., Polcher, J., Friedlingstein, P., Ciais, P., Sitch, S., and Prentice, I. C.: A dynamic global vegetation model for studies of the coupled atmosphere-biosphere system, Global Biogeochem. Cy., 19, GB1015, doi:10.1029/2003GB002199, 2005.

Laureysens, I., Deraedt, W., Indeherberge, T., and Ceulemans, R.: Population dynamics in a 6-year old coppice culture of poplar. I. Clonal differences in stool mortality, shoot dynamics and shoot diameter distribution in relation to biomass production, Biomass Bioenerg., 24, 81-95, 2003.

Muhle Larsen, C.: Considérations sur l'amélioration du genre Populus et spécialement sur la section Aigeiros, in: Proceedings of the World Consultation on Forest Genetics and Tree Improvement, Stockholm, Sweden, 23-30 August 1963, FAO, Rome, Italy, 1963.

Njakou Djomo, S., Ac, A., Zenone, T., De Groote, T., Bergante, S., Facciotto, G., Sixto, H., Ciria Ciria, P., Weger, J., and Ceulemans, R.: Energy performances of intensive and extensive short rotation cropping systems for woody biomass production in the EU, Renewable and Sustainable Energy Reviews, 41, 845-854, doi:10.1016/j.rser.2014.08.058, 2015.

Pontailler, J. Y., Ceulemans, R., and Guittet, J.: Biomass yield of poplar after five 2-year coppice rotations, Forestry, 72, 157-163, 1999.

Reichstein, M., Falge, E., Baldocchi, D., Papale, D., Aubinet, M., Berbigier, P., Bernhofer, C., Buchmann, N., Gilmanov, T., Granier, A., Grunwald, T., Havrankova, K., Ilvesniemi, H., Janous, D., Knohl, A., Laurila, T., Lohila, A., Loustau, D., Matteucci, G., Meyers, T., Miglietta, F., Ourcival, J. M., Pumpanen, J., Rambal, S., Rotenberg, E., Sanz, M., Tenhunen, J., Seufert, G., Vaccari, F., Vesala, T., Yakir, D., and Valentini, R.: On the separation of net ecosystem exchange into assimilation and ecosystem respiration: review and improved algorithm, Glob. Change Biol., 11, 1424-1439, 2005.
Richardson, A. D., Hollinger, D. Y., Burba, G. G., Davis, K. J., Flanagan, L. B., Katul, G. G., Munger, J. W., Ricciuto, D. M., Stoy, P. C., Suyker, A. E., Verma, S. B., and Wofsy, S. C.: A multi-site analysis of random error in tower-based measurements of carbon and energy fluxes, Agr. Forest Meteorol., 136, 1-18, doi:10.1016/j.agrformet.2006.01.007, 2006.

Verlinden, M. S., Broeckx, L. S., Wei, H., and Ceulemans, R.: Soil $\mathrm{CO}_{2}$ efflux in a bioenergy plantation with fast-growing Populus trees - influence of former land use, inter-row spacing and genotype, Plant Soil, 369, 631-644, doi:10.1007/s11104-013-1604-5, 2013a.

Verlinden, M. S., Broeckx, L. S., Zona, D., Berhongaray, G., De Groote, T., Camino Serrano, M., Janssens, I. A., and Ceulemans, R.: Net ecosystem production and carbon balance of an SRC poplar plantation during its first rotation, Biomass Bioenerg., 56, 412-422, doi:10.1016/j.biombioe.2013.05.033, 2013 b.

Zervos, A., Lins, C., and Tesnière, L.: EU Roadmap - Mapping Renewable Energy Pathways towards 2020, European Renewable Energy Council, Brussels, Belgium, 104, 2011.

Zona, D., Janssens, I. A., Aubinet, M., Gioli, B., Vicca, S., Fichot, R., and Ceulemans, R.: Fluxes of the greenhouse gases $\left(\mathrm{CO}_{2}\right.$, $\mathrm{CH}_{4}$ and $\mathrm{N}_{2} \mathrm{O}$ ) above a short-rotation poplar plantation after conversion from agricultural land, Agr. Forest Meteorol., 169, 100 110, doi:10.1016/j.agrformet.2012.10.008, 2013a.

Zona, D., Janssens, I. A., Gioli, B., Jungkunst, H. F., Serrano, M. C., and Ceulemans, R.: $\mathrm{N}_{2} \mathrm{O}$ fluxes of a bio-energy poplar plantation during a two years rotation period, GCB Bioenergy, 5, 536-547, doi:10.1111/gcbb.12019, 2013b.

Zona, D., Gioli, B., Fares, S., De Groote, T., Pilegaard, K., Ibrom, A., and Ceulemans, R.: Environmental controls on ozone fluxes in a poplar plantation in Western Europe, Environ. Poll., 184, 201-210, 2014. 